\title{
Ultrasonic Dyeing of Enzyme Treated Organic Cotton Using Nyctanthes Arbor-Tristis
}

\author{
R. RAJIV GANDHI, J. SURESH, S. GOWRI, \\ S. SELVAM and M. SUNDRARAJAN*
}

Department of Industrial Chemistry, Advanced Green Chemistry Lab, School of Chemical Sciences, Alagappa University, Karaikudi -3, Tamilnadu, India drmsgreenchemistrylab@gmail.com

Received 8 September 2012 / Accepted 20 October 2012

\begin{abstract}
Bleaching of organic cotton fabric can be done with hydrogen peroxide in which Catalase, a non-toxic, environmentally friendly biocatalyst is used to remove the residual $\mathrm{H}_{2} \mathrm{O}_{2}$ in a cost effective way for the better improvement of the cellulosic fabric properties. Enzyme treated organic cotton fabric was dyed with a natural dye obtained from orange corolla tube of Nyctanthes arbor-tristis flower with the use of ultrasonic power $(38.5 \mathrm{kHz}$ and $500 \mathrm{~W})$ and Conventional heating conditions. Ultrasonic power dyed fabric was compared with conventional dyeing by studying their dyeability. Optical density measurements were done for both dyed organic cotton samples. The ultrasound assisted dyeing process gave better dye absorption and fastness properties than that of conventional method using mordants.
\end{abstract}

Keywords: Organic cotton, Catalase, Nyctanthes arbor-tristis, Mordants, Ultrasonic dyeing

\section{Introduction}

Ultrasound technique has been studied and used for a variety of applications in liquids, dispersions and polymers. Ultrasonic holds a promise in applications in the field of textiles. Inspite of the varied advantages and simplicity of ultrasonic dyeing, there are many potential advantages offered by the use of ultrasound in textile wet processing ${ }^{1-3}$. Researchers have reported the benefits of ultrasonic dyeing in different aspects such as energy savings by dyeing at lower temperatures, reduced processing times, environmental improvements by reduced consumption of auxiliary chemicals, process enhancement by allowing real-time control of colour shade and lower overall processing costs, thereby increasing industry competitiveness. A fundamental understanding of the relative operative processes is needed so that meaningful application of ultrasonic in textile wet processing can be made ${ }^{4-5}$. 
Enzymes are becoming increasingly important in sustainable technology and green chemistry ${ }^{6}$. Especially, in textile, the use of enzymes has a long tradition. The enzymatic desizing of cotton with $\alpha$-amylases is an art since many decades ${ }^{7}$. Moreover, cellulases, pectinases, hemicellulases, lipases and catalases are used in different cotton pre-treatment and finishing processes ${ }^{8}$. Raw cotton fabric is usually bleached using hydrogen peroxide and the excess hydrogen peroxide should be removed to prevent reaction with dye. In traditional method, excess $\mathrm{H}_{2} \mathrm{O}_{2}$ removed by boiling with sodium bisulphate and repeated rinsing of the fabric with water a number of times. In this case, large amounts of water (up to $40 \mathrm{~L} / \mathrm{kg}$ of fabric) are required for rinsing and resulting in discharge of large volumes of wastewater.

Contemporary biotechnology offers the opportunity to reduce the large water consumption required for washing by the use of catalases for peroxide decomposition. Catalase is known for its ability to catalyse the conversion of $\mathrm{H}_{2} \mathrm{O}_{2}$ to water and gaseous oxygen $^{9,10}$. The application of enzymes has many advantages compared to conventional and non-enzymatic processes. Enzymes can be used in catalytic reaction at low temperatures and $\mathrm{pH}$-values near to neutral and their high substrate selectivity allows a very gentle treatment of the goods. Moreover, enzymes are biologically degradable and handled without risk ${ }^{11,12}$.

Cotton is an abundant natural fibre which consists of practically pure cellulose (about 88$96 \%)^{13}$. High levels of agrochemicals are used in the production of non-organic, conventional cotton. Cotton production uses more chemicals per unit area than any other crop and accounts in total about $16 \%$ of the world's pesticides but we used environment friendly organic cotton fabric, which was cultivated without using pesticides, chemicals and synthetic fertilizers ${ }^{14,15}$. Parijataka (Nyctanthes arbor-tristis) is one of the most valuable gifts of nature to mankind. It is a short stalk flower with two white petals and orange corolla tube. The bright orange colour tube size is $1 / 2$ to $3 / 4$ inches. It contains colouring matter nyctanthin which is identical with cracetin $\left(\mathrm{C}_{20} \mathrm{H}_{24} \mathrm{O}_{4}\right)$ from salfron ${ }^{16-18}$. In the view of polluting aspects of synthetic dyes and long term non-sustainable nature of these petrochemical derivatives, natural dyes are gaining importance. Presently there is an excessive use of synthetic dyes, which is estimated around 10,000,000 tons per annum ${ }^{17}$. However there is a need to improve the dye fastness and the reproducibility of the dyeing process $^{18}$. Generally, problems in dyeing with natural dyes are related to low exhaustion of dyes and to the poor fastness of the dyed fabrics. Attempts to overcome these problems have been mainly focused on the use of metallic salts as mordants ${ }^{19,20}$.

The purpose of this study was to investigate the dyeing and fastness properties of natural colourant extracted from parijataka (Nyctanthes arbor-tristis) flower on enzyme treated organic cotton fabric using eco-friendly mordants in both conventional and ultrasonic power dyeing methods.

\section{Experimental}

Scoured organic cotton fabrics were purchased from Tirupur Industries, India. The orange corolla tube of Nyctanthes arbor-tristis flowers were collected from our local residential area was used as a colouring substance to this work. Mordants including stannous chloride, ferrous sulphate, cow dung and tannic acid were used. Hydrogen peroxide, sodium carbonate, sodium hydroxide, sodium bisulphate, acetic acid were used without further purification. Catalaseenzyme was used in bleaching process, purchased from Hi Media, India. All other chemicals used were laboratory grade reagents purchased from Merck, India Pvt. Ltd.

Many reports related to mordant research were focused on the effect of synthetic mordant (Aluminum sulphate, copper sulphate, lead acetate and potassium dichromate etc.,) and not much effort had been made to study the effect of natural mordant in dyeing industry. 
Considering the importance of the natural dyes with natural mordant and the harmful effect of synthetic dyes with synthetic mordant, an effort had been made to formulate an ecofriendly herbal dye with a natural mordant ${ }^{21,22}$.

\section{Methods}

\section{Bleaching}

The scoured organic cotton fabric was entered into the bleaching bath containing the required amount of $\mathrm{H}_{2} \mathrm{O}_{2}$ (3\%), $\mathrm{NaOH}(4 \%)$ and $\mathrm{Na}_{2} \mathrm{CO}_{3}(4 \%)$. The MLR was kept as 1:30 and the bleaching was carried out at $60{ }^{\circ} \mathrm{C}$ for 40 minutes, then the bleached organic cotton fabric was washed with water.

\section{$\mathrm{NaHSO}_{4}$ treatment}

After hydrogen peroxide bleaching, the bleached fabric was entered into a vessel containing the required amount of sodium bisulphate (5\%) for 20 minutes at $45{ }^{\circ} \mathrm{C}$ to neutralize the residual $\mathrm{H}_{2} \mathrm{O}_{2}$, then the fabric was washed with water repeatedly to remove the excess chemicals and then dried.

\section{Enzyme treatment}

Hydrogen peroxide bleached organic cotton fabric was entered into a bath containing 4\% catalase enzyme and the bath was kept at room temperature for 30 minutes. After this treatment, there is no residual hydrogen peroxide in the bath since it was converted in to water and oxygen molecules by Catalase. Here it was not necessary to wash the fabric because $\mathrm{H}_{2} \mathrm{O}_{2}$ was converted in to water.

$$
\mathrm{H}_{2} \mathrm{O}_{2} \stackrel{\text { Catalase }}{\longrightarrow} \mathrm{H}_{2} \mathrm{O}+1 / 2 \mathrm{O}_{2}
$$

\section{Extraction of natural colouring matter from Nyctanthes arbor-tristis flowers}

Flowers of coral jasmine (Nyctanthes arbor - tristis) were collected from our local residential area. Flower of coral jasmine was segregated into two parts (based on the colour) namely orange corolla tube and white corolla lobe. Only the orange corolla tubes were used to dyeing, tubes were dried at room temperature for 7 days and finely powdered, a weighed quantity of powdered dye was used for dyeing.

\section{Dyeing}

Enzyme bleached organic cotton was dyed by simultaneous mordanting method by keeping ML ratio as 1:20. The fabric was kept in the dye bath for 45 minutes at $80{ }^{\circ} \mathrm{C}$ in presence of $5 \%$ of dye, $3 \%$ of mordant, $10 \%$ sodium chloride and $3 \%$ sodium carbonate with constant stirring. The dyed material was washed with cold water and dried at room temperature. The same procedure was followed for all mordants.

\section{Ultrasonic dyeing}

Thermostated CREST bench top 575 HT ultrasonic cleaner of capacity 5.75 with $38.5 \mathrm{kHz}$ and with a maximum $500 \mathrm{~W}$ output was used for the ultrasonic dyeing. According to the standard dyeing protocol, dye bath was prepared in a $100 \mathrm{ml}$ beaker containing $5 \%$ of dye, $3 \%$ of mordant, $10 \%$ sodium chloride and $3 \%$ sodium carbonate and ML ratio as 1:30. The $\mathrm{pH}$ of the bath was maintained as 9.2 by adding $2 \%$ aqueous $\mathrm{NaCl}$, finally the enzyme treated fabric was immersed in the beaker. The dye bath containing the enzyme treated fabric was then subjected to dyeing using the ultrasonicator with working frequency of 27$30 \mathrm{mHz}$ at $160 \mathrm{~V}$ under a controlled water level at about 2-3 $\mathrm{cm}$ from the bottom of the bath. The fabric was dyed for 60 minutes using the mentioned sonic power level. 


\section{Weight loss}

The percentage of weight loss was calculated by using the formula,

Weight Loss $=\left(\mathrm{W}_{1}-\mathrm{W}_{2}\right) / \mathrm{W}_{1} \times 100$

Where, $\mathrm{W}_{1}=$ Weight of the fabric before enzyme treatment, $\mathrm{W}_{2}=$ Weight of the fabric after enzyme treatment

\section{Optical density}

The exhaustion values of dyed samples were measured by taking the absorbance of the dye liquor sample (before and after dyeing) using an UV-visible spectrometer (Jasco V-530) at a wave length of maximum absorbance $\left(\lambda_{\max }\right)$ concerned. The optical density of original dye and spent dye liquor were observed and dye uptake was calculated using the following formula;

Where,

Dye uptake $=$ A1-A2 $/$ A $1 \times 100$

A1 $=$ OD of original dye

$\mathrm{A} 2=\mathrm{OD}$ of spent dye liquor

\section{Washing fastness}

Washing fastness of all dyed samples was measured by the ISO 105-C03 testing method. Dyed samples were taken, stitched with one of the shorter side of the adjacent bleached fabric and put in to the bath containing $3 \mathrm{~g} / \mathrm{L}$ of soap, $2 \mathrm{~g} / \mathrm{L}$ of sodium carbonate and 1:30 MLR ratio at $60^{\circ} \mathrm{C}$ for 30 minutes. Then the specimen was washed with hot water, cold water and dried. The change in shade and stain was compared for both conventional and ultrasonic dyed samples.

\section{Light fastness}

Dyed samples were cut and placed on a cardboard, one-half of the samples was masked and the other was exposed to sunlight for different (1-6, 1-12, 1-18) hours. The light fastness of the samples was assessed according to their degree of fading using grey scale.

\section{Results and Discussion}

This study illustrates the use of an eco-friendly alternative for the neutralisation of organic cotton bleach using enzyme. The enzyme treated organic cotton was dyed with the ecofriendly dye Parijataka by two different conditions i.e with and without ultrasound and the different parameters were studied for both methods. UV-Visible spectral analysis of the dye solution shows the absorption at blue region with a wavelength over the range of 430-450 nm which confirms ${ }^{23}$ the appearance of yellow colour of parijataka dye (Figure 1). So this area was chosen for further investigation.

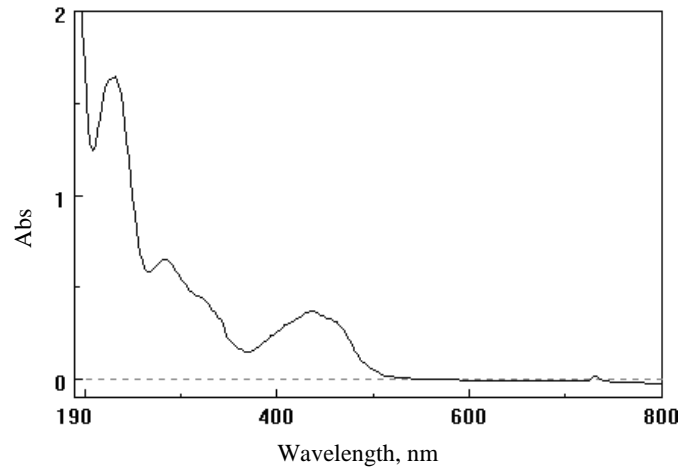

Figure 1. UV-Visible spectrum of Nyctanthes arbor - tristis 
The dye uptake was measured from the values of Optical Density (OD) which is shown in Table 1. The initial OD of dye liquor value with salt is 4.27. Among the four mordants, cow dung mordanted fabric showed less dye uptake than the other mordants. Enzyme treated organic cotton samples showed better dye uptake with all mordants on ultrasonic power dyeing than conventional process. In ultrasonic method the stable cavitations bubbles oscillate and which is responsible for the enhanced molecular motion and stirring effect of ultrasound. In this organic cotton dyeing, ultrasonic wave stays in plant cell longer and deeper than what an electromagnetic wave can penetrate also effectively.

Table 1. Dye uptake ranges of samples from optical density

\begin{tabular}{ccccc}
\hline \multirow{2}{*}{ Mordants } & \multicolumn{2}{c}{ OD of spent dye liquor } & \multicolumn{2}{c}{ Dye Uptake } \\
\cline { 2 - 5 } & CD & UD & CD & UD \\
\hline Ferrous sulphate & 2.0045 & 1.6143 & 53.05 & 62.19 \\
Stannous chloride & 2.0051 & 1.5942 & 53.04 & 62.66 \\
Cow dung & 2.0258 & 1.6876 & 52.55 & 60.47 \\
Tannic acid & 1.9965 & 1.5136 & 53.71 & 64.55 \\
\hline
\end{tabular}

Weight loss

$C D=$ Conventional Dyeing, $U D=$ Ultrasonic dyeing

The organic cotton fibres showed greater weight loss in the conventional enzymatic bleaching treatment (catalase) than in the $\mathrm{NaHSO}_{4}$ treatment. This means that the bleaching treatment removes more impurities from the surface. Catalase acts in cold water and thus saves valuable energy. A small dose of catalase enzyme is capable of decomposing hydrogen peroxide to water and oxygen. After catalase treatment, rinsing is not at all required there by a huge quantity of water is saved. Thus the use of catalase not only saves water, time and energy but also reduces the pollution load considerably.

\section{Fastness properties}

In conventional heating method light fastness is similar for all samples, irrespective of bleaching method and use of mordants (Table 2). It is observed that almost all the treated fibres have moderate light fastness ranging from 2-4. But in ultrasonic power dyeing, all the mordants are having good fastness properties particularly tannic acid and stannous chloride. Almost all the treated fibres have moderate light fastness ranging from 5-7 was observed.

Table 2. Fastness properties of both dyed samples

\begin{tabular}{ccccccccccc}
\hline \multirow{2}{*}{ Mordants } & \multicolumn{4}{c}{ Light fastness } & \multicolumn{4}{c}{ Washing fastness } \\
\cline { 2 - 11 } & \multicolumn{3}{c}{ 6, h } & \multicolumn{1}{c}{ 12, h } & \multicolumn{1}{c}{ 18, h } & \multicolumn{3}{c}{ Change in shade } & Change in stain \\
\hline & CD & UD & CD & UD & CD & UD & CD & UD & CD & UD \\
\hline $\begin{array}{c}\text { Ferrous } \\
\text { sulphate }\end{array}$ & 4 & $5-7$ & 3 & $5-6$ & 3 & 5 & 3 & $3-4$ & 2 & 4 \\
$\begin{array}{c}\text { Stannous } \\
\text { chloride }\end{array}$ & $3-4$ & $5-6$ & 3 & $5-6$ & 3 & 5 & 2 & $3-4$ & 3 & 4 \\
Cow dung & $2-3$ & $5-6$ & $2-3$ & 5 & 2 & $4-5$ & 3 & 4 & 2 & $3-4$ \\
Tannic acid & $3-4$ & 7 & 3 & $6-7$ & $2-3$ & $6-7$ & 2 & 4 & 3 & $4-5$ \\
\hline
\end{tabular}

$C D=$ Conventional Dyeing, $U D=$ Ultrasonic dyeing

In general wash fastness for majority of the natural dyes was poor. But in ultrasonic treatment wash fastness values of dyed samples with various mordants showed good results (3-5) particularly tannic acid and stannous chloride mordanted fabrics exhibit good affection with dye molecules. In conventional dyed fabric wash fastness values were not good (2-3). 
This indicates that there may be a poor fixation of the dye on enzyme treated fibres in conventional heating.

Performance of ultrasonic dyeing of organic cotton sample exhibits better result than conventional heating method while comparing the different parameters such as dye uptake, and fastness properties. According to the use of different mordants, the increasing order of different parameters is same for both ultrasonic and conventional heating method i.e., tannic acid mordant shows better result in both methods.

\section{Conclusion}

It can be concluded that enzymatic bleaching neutralisation of organic cotton is very interesting alternative to conventional bleaching type. The ultrasonic dyeing of cotton gave rapid dye adsorption kinetics and total higher adsorption than conventional dyeing for all the four mordants. Dyeing kinetics of enzyme treated cotton fabrics were compared for both the methods. The dye uptake reveals that the enhanced dye uptake showing the efficiency of sonicator. Thus the net enhancement of dye uptake and wash fastness values has been found to be best for tannic acid compared to other mordants. So, the tannic acid-ultrasonic-dye combination method offers an environmentally benign alternative to the metal mordanted natural dyeing. It is hoped that parijataka dye extract will definitely find great use in cotton industry especially in yellow colour range dyeing. Dye uptake and surface lustre were very good in organic cotton fabric. So, from our ecological point to avoid synthetic fertilizers and pesticides we suggest that replacement of cotton by organic cotton.

\section{Acknowledgement}

Authors would like to thank Alagappa University Research Fund (AURF), Alagappa University, Karaikudi, Tamilnadu, India for their financial support and providing excellent facilities for the above work. We would like to thank DST-FT \& UGC- New Delhi for their encouragement.

\section{References}

1. Thakore K A, Indian J Textile Res., 1988, 13, 133, 208.

2. Shimizu Y, Yamamoto R and Shimizu H, Textile Res J., 1989, 59, 684.

3. Henglein A and Gutierrez M, J Phys Chem., 1990, 94(12), 5169-5172.

4. Cost M, Mills G, Glisson P and Lakin J, Chemosphere, 1993, 27(9), 1737-1743.

5. $\quad$ Riesz P and Kondo T, Free Radic Biol Med., 1992, 13(3), 247-270.

6. $\quad$ Festel G, Knöll J, Götz H and Zinke H, Chemie Ingenieur Technik, 2004, 76(3), 307-312.

7. $\quad$ Marcher D, Hagen H A and Castelli S, ITB Veredlung, 1993, 39(2), 20-32.

8. Meyer-Stork L S, Maschen-Industrie, 2002, 52(5), 32-35.

9. Akertek E and Tarhan L, Appl Biochem Biotechnol., 1995, 50, 291-303.

10. Goldstein L and Maneke G, Applied Biochemistry Engineering, Edited by L. Wingard; 1976, 1, 23-127.

11. Uhlig H and Hanser Verlag C, Enzyme Arbeiten Für uns, München, 1991.

12. Ruttloff H, Behr's Verlag Industrielle Enzyme, Hamburg, 1994.

13. Lewis R J, Hawley's Condensed Chemical Dictionary. $12^{\text {th }}$ Ed., New York: Van Nostrand Reinhold, 1993.

14. Peppas A, Conventional Spinning in Cotton System, $2^{\text {nd }}$ Edition, Athens, 1998.

15. Myers D and Stolton S, Organic Cotton, 1999. 
16. Siddiqui I and Siddiqui K, Man-Made Textiles India, 2009, 56, 74-79.

17. Sundrarajan M, Rajiv Gandhi R, Rukmani A, Suresh J, Selvam S and Gowri S, Chem Sci Trans., 2012, 1(2), 440-446.

18. Sundrarajan M, Selvam S, Rajiv Gandhi R and Suresh J, Int J Curr Res., 2011, 3, 363-367.

19. Darvekar M, Ghorpade B and Vankar P S, Colourage, 2000, 8, 27-30.

20. Chairat M, Bremner J B and Chantrapomma K, Fibres Polym., 2007, 8(6), 613-619.

21. Tsatsaroni E G and Eleftheradis I C, J Soc Dyers Colour., 1994, 110, 313.

22. Bayer E, Egeter H, Fink A and Wegmann K, Angew Chem Int Edition, 1996, 5, 791-798.

23. Trotman E R, Dyeing and Chemical Technology of Textile Fibres, Charles Griffin \& Co Ltd, London, 1975, 5, 456-69. 